adrenaline injection were a few abnormal vessels identified in the region of the calcification, which showed partial vasoconstriction. This doubtful finding and the unexplained renal parenchymal calcification prompted us to ask for an exploration of the right kidney. A radical nephrectomy was carried out because of a mass $4 \mathrm{~cm}$ in diameter suggestive of an hypernephroma confined to the middle portion of the kidney. Examination by light microscopy showed a clear-cell renal carcinoma. The unaffected renal tissue showed focal glomerular obsolescence and minor changes in the remaining glomeruli, tubular atrophy with intraluminal casts, interstitial fibrosis, and irregular hyaline thickening of arterioles. Special stainings for amyloid on renal tissue and on a surgical liver specimen were negative.

The changes that occurred after operation are depicted in the table. Three months after nephrectomy creatinine clearance had increased but the patient still had $x$-chains in his serum and urine as well as reduced concentrations of serum urate and phosphate. He was seen again two years later, when $x$-chains were no longer present either in urine or in serum and serum phosphate and urate concentrations had returned to normal values, with clearances and fractional excretions appropriate to the concurrent creatinine clearance. At the last study in February 1981, nearly five years after the operation, the patient appeared well. Arterial blood pressure was $170 / 100 \mathrm{~mm} \mathrm{Hg}$, and fasting plasma glucose concentration was $12.7 \mathrm{mmol} / 1(230 \mathrm{mg} / 100$ $\mathrm{ml}$ ). Light chains were still undetectable either in serum or in spot urine specimens; the tenfold concentrated urinary specimen contained both $x$-chains and $\lambda$-chains.

\section{Discussion}

Along with renal tubular dysfunction, manifested by low serum concentrations of urate and phosphate with clearances inappropriately high with respect to that of creatinine, this patient had $x$-chains in both serum and urine. $\lambda$-Chains were undetectable even in urine samples concentrated several folds. Hence the light-chain proteinuria was due to overproduction with overflow excretion of the $M$ component. A frequent association between monoclonal gammopathy and non-reticular cancers, especially of the colon and biliary tracts, has long been recognised. ${ }^{3}$ It has been suggested that tumoural antigens might cause stimulation of immunocytes or that the neoplastic cells themselves might produce the $\mathrm{M}$ component. ${ }^{3}$ Both monoclonal gammopathy and cancer, however, prevail in old age, and a chance association between them cannot be excluded. In our patient the disappearance of $x$-chains from serum after surgical treatment argues in favour of a causal relation between the renal tumour and the overproduction of the $M$ component.

Much experimental and clinical evidence shows that lightchain overproduction may induce renal tubular dysfunction. ${ }^{4}$ In this patient the improvement in tubular dysfunction after $x$-chains had disappeared from serum may be interpreted as evidence of light chains exerting a nephrotoxic effect.

Requests for reprints should be addressed to: Prof $\mathrm{Q}$ Maggiore, Centro di Fisiologia Clinica del CNR, Via Sbarre Inferiori 39, 89100 Reggio Calabria, Italy.

\section{References}

${ }^{1}$ Steele TH, Riesselbach RE. The contribution of residual nephrons within the chronically diseased kidney to urate homeostasis in man. $\mathrm{Am} \mathcal{F} \mathrm{Med}$ $1967 ; 43: 876$.

${ }^{2}$ Popovtzer MM, Shaineik H, Massry SG, Kleeman CR. Divalent ion excretion in chronic renal disease : relation to degree of renal insufficiency. Clin Sci 1970;38:297.

3 Waldenström JG. Benign monoclonal gammopathies. In: Azar HA, Potter M, eds. Multiple myeloma and related disorders. Vol 1. Hagerstown, Md: Harper and Row, 1973:247-86.

4 Smithline N, Kassirer JP, Cohen JJ. Light-chain nephropathy. N Engl f Med 1976:294:71-4

${ }^{5}$ Maldonado JE, Velosa JA, Kyle RA, Wagoner RD, Holley KE, Salassa RM. Fanconi syndrome in adults. $A m \mathcal{F} \operatorname{Med} 1975 ; 58: 354-64$.

(Accepted 11 fune 1981)

\title{
Oxytocin enhances onset of lactation among mothers delivering prematurely
}

\author{
H RUIS， R ROLLAND，W DOESBURG，G BROEDERS， R CORBEY
}

\begin{abstract}
In a double-blind group sequential trial the efficiency of an oxytocin nasal spray in enhancing lactation was studied during the first five days after delivery in women who had given birth prematurely. The cumulative volume of breast milk obtained between the second and fifth days after delivery was 3.5 times greater in primiparas given oxytocin than in primiparas given placebo.
\end{abstract}

Department of Obstetrics and Gynaecology, Groot Ziekengasthuis, 's-Hertogenbosch, the Netherlands

H RUIS, MD, registrar

G BROEDERS, MD, gynaecologist

R CORBEY, MD, gynaecologist

Department of Obstetrics and Gynaecology, Division of Gynaecologic Endocrinology and Infertility, University Hospital, Nijmegen, the Netherlands

R ROLLAND, MD, professor of gynaecology, endocrinology, and infertility

Department of Statistical Consultation, University, Nijmegen, the Netherlands

W DOESBURG, consulting statistician
There was no significant difference in the composition of the milk between the untreated women and those given oxytocin.

The results of this study show that oxytocin nasal spray is an effective and safe means of enhancing lactation in women using a breast pump.

\section{Introduction}

The feeding of premature infants has long been controversial among neonatologists. ${ }^{1}$ The protective properties of breast milk against sepsis $^{23}$ and necrotising enterocolitis ${ }^{45}$ are well recognised, and breast milk is more digestible than artificial milks. Workers are agreed on the desirability of using fresh milk for feeding premature infants when the donor is the infant's own mother. ${ }^{6}$ The idea that the protein content of human milk is low seems to have been refuted by Atkinson et $a l,{ }^{7}$ who showed that the milk of mothers of premature infants has a higher nitrogen concentration than normal.

All clinical workers know that establishing sufficient lactation by using a breast pump or manual expression is difficult, especially in primiparas. ${ }^{8} 9$ There are three methods of improv- 
ing lactation. The first is to let the infant suckle or to pump the breasts more frequently. This is the most physiological method, but in practice it is almost impossible to pump the breasts more than four to six times a day. The second method is to prescribe pharmacological agents to increase plasma prolactin concentrations-for example, sulpiride, ${ }^{10}$ metoclopramide, ${ }^{11}$ or phenothiazines. These drugs have the disadvantage of being excreted in the milk and may do harm, especially to the premature infant. The effects of these pharmacological agents when used to enhance lactation in women using the breast pump have not been determined. The third method is to improve the let-down of milk by giving oxytocin. This seems a rational approach since most women find the breast pump repulsive and the milk ejection reflex is thus inhibited. Since a negative feedback system for oxytocin does not exist ${ }^{12}$ the mothers' let-down reflex is not suppressed when exogenous oxytocin is used. Improvements in lactation caused by exogenous oxytocin in normal lactation are well known. ${ }^{13}{ }^{14}$ Nevertheless, oxytocin has never been greatly used for lactational problems.

In the present study we aimed at examining the effect on lactation of $3 \mathrm{U}$ oxytocin administered by nasal spray at each pumping session to women who had given birth prematurely and used a breast pump to induce lactation. The amount of milk produced and the composition of the milk was compared between women treated with oxytocin and untreated women. The composition of the milk was also compared with milk of women who had delivered at term.

\section{Subjects and methods}

All women who participated in this study had given birth prematurely (before 38 weeks) to an infant weighing less than $2200 \mathrm{~g}$ and were lactating for the first time. After consultation with the neonatologist about whether she should breast-feed the mother was asked to participate in this study. She was fully informed of the study and supplied with written information. All subjects were supplied with their own spray bottle containing oxytocin (Syntocinon, Sandoz) 40 $\mathrm{U} / \mathrm{ml}$ or a blank solution. Randomisation was performed by a third party in such a way that in each sequential group of four subjects two received an oxytocin spray. Allocation was double blind.

In each case the infant continued to receive intensive care and was unable to suck the breasts for at least five days. During these five days the breasts were pumped four times a day using an Egnell breast pump. Just before the pump was applied the nasal spray was used once in each nostril (total $3 \mathrm{U}$ oxytocin), after which one of the breasts was pumped for 10 minutes. This procedure was repeated before the other breast was pumped. The amount of milk pumped from each breast was recorded for all sessions during the first five days after birth. Side effects were noted. During the afternoon session on the third and fifth days a $20 \mathrm{ml}$ mixed milk sample was taken and frozen at $-20^{\circ} \mathrm{C}$ for analysis.

Four women who had given birth at term and were breast-feeding in the normal way had their breasts pumped once in the afternoon of the third and fifth days after birth. These samples were also frozen at $-20^{\circ} \mathrm{C}$.

The design of the trial and the statistical evaluations made were unusual and are described below. We wished to study separately the effects of oxytocin on primiparas and on multiparas breast-feeding for the first time. For the statistical analysis the total amount of milk obtained over the 12 pumping sessions on the third, fourth, and fifth days after delivery was the primary variable. The first day after delivery was excluded because not all women had four pumping sessions on that day. The second day was also excluded because the late start on the first day might possibly have had an effect on milk production on the second day.

The main goal of the study was to assess the effect of oxytocin on lactation especially in the primiparas. Therefore, we designed a trial that used a minimal number of subjects and yet was still practicable. The idea was to stop the trial as soon as convincing evidence was obtained of the expected beneficial effect. Thus a group sequential trial seemed suitable. Sequentially a group of four women (two given oxytocin, two untreated) were brought into the trial, and after the data had been collected the total amount of milk pumped over the third, fourth, and fifth days after delivery was compared between the oxytocin-treated and the untreated women by means of Student's two-sample test. Because of its variance stabilising effect Student's test was performed after a square-root transformation.

Beforehand we had decided to limit the study to a maximum of 28 women (seven groups) within each parity class. According to Pocock, ${ }^{15}$ within a parity class the study would be closed as soon as the twosided p value obtained using Student's test dropped lower than 0.013 . The significance for this test procedure equals approximately 0.05 . Should Student's test result in a p value lower than 0.013 and the average amount of milk in the oxytocin-treated group be larger than that in the placebo group, the improving effect of oxytocin would be significant. But should the $p$ value after the final group be larger than 0.013 the supposed effect of oxytocin would be considered to have been inadequately shown and the difference in milk production between the two treatment groups would not be significant.

The following components of breast milk were analysed at the Netherlands Institute for Dairy Research. The ash content was measured as the remains of milk treated at a temperature of $550^{\circ} \mathrm{C}$ for three hours. Fat was measured using the method of Röse-Gottlieb according to the International Dairy Federation (JDF norm IA, 1969) except that we used $2 \mathrm{~g}$ milk instead of $10 \mathrm{~g}$ and added $1.5 \%$ sodium chloride solution to $10 \mathrm{ml}$. Nitrogen concentration was analysed colorimetrically as described. ${ }^{16}$ In some samples a complete Kjeldahl analysis was carried out with similar results. The final results are given as the protein content, which was obtained by multiplying the nitrogen content by 6.38 . Lactose was measured by a reductometric method according to Luff-Schoorl with the modification of Weide and Dagneaux. ${ }^{16 a}$ Sodium and potassium were analysed by a flame photometer after dilution of the samples $1: 1000$ with $0.05 \%$ cesium chloride solution. By using Southgate and Durnin's formula ${ }^{17}$ we calculated the energy values from the lactose, fat, and protein contents.

\section{Results}

After we had studied the second group of primiparas (eight subjects) the $p$ value equalled 0.0001 (table I), and we therefore concluded that significantly more milk was removed during the third to fifth days after delivery in the women given oxytocin than in those given placebo. The figure shows the individual results. Table I also shows the mean cumulative amount of milk removed by breast pump in the treated and untreated primiparas during the second to fifth days after delivery and the significance of the difference between the two groups after each day. The cumulative volume of breast milk obtained between the second and fifth days after delivery was 3.5 times greater in the women given oxytocin.

During the period when these eight primiparas were being studied a test on four multiparas breast-feeding for the first time was com-

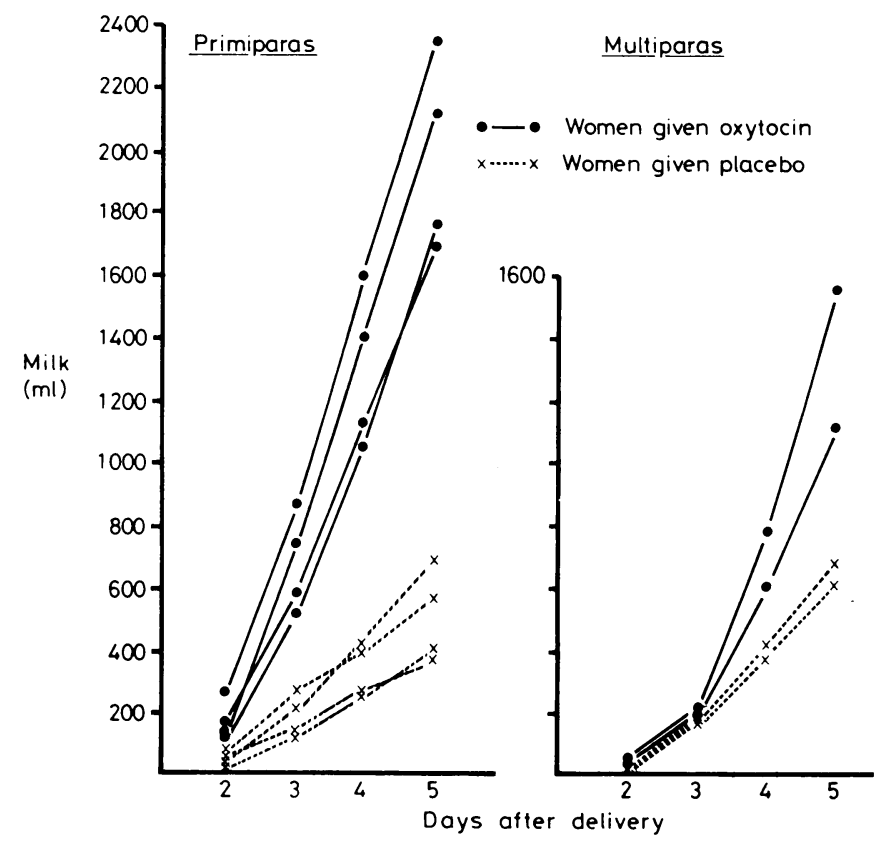

Cumulative amount of milk obtained during second to fifth days after delivery by using breast pump on four occasions each day in primiparas and in multiparas breast-feeding for first time given oxytocin or placebo. 
pleted (figure) and a p value of 0.068 obtained. We decided then that the beneficial effect of oxytocin in women using the breast pump was so obvious that there was no sense in continuing the trial.

Table II shows that the effect of oxytocin was greater in primiparas than in multiparas breast-feeding for the first time. In the untreated

TABLE I-Mean $\$ S D$ cumulative amounts of milk $(\mathrm{ml})$ obtained from primiparas during second to fifth days after delivery

\begin{tabular}{lccc}
\hline & $\begin{array}{c}\text { Placebo treated } \\
(\mathrm{n}=4)\end{array}$ & $\begin{array}{c}\text { Oxytocin treated } \\
(\mathrm{n}=4)\end{array}$ & $\begin{array}{c}\text { Significance } \\
(\mathrm{p})^{*}\end{array}$ \\
\hline Day 3+4+5 & $460 \div 137$ & $1795: 270$ & 0.0001 \\
Day 2 & $50 \div 21$ & $169: 67$ & 0.013 \\
Day 2+3 & $185: 59$ & $680: 159$ & $0 \cdot 001$ \\
Day 2+3+4 & $336 \pm 92$ & $1291: 252$ & $0 \cdot 0004$ \\
Day 2+3+4+5 & $510 \pm 142$ & $1964: 308$ & 0.0002 \\
\hline
\end{tabular}

${ }^{*}$ Each $\mathbf{p}$ value is the result of Student's test performed after square-root transformation of the total amount of milk (group sequential analysis).

\begin{tabular}{|c|c|c|}
\hline & $\begin{array}{l}\text { Placebo } \\
\text { treated }\end{array}$ & $\begin{array}{c}\text { Oxytocin } \\
\text { treated }\end{array}$ \\
\hline \multicolumn{3}{|c|}{ Primiparas } \\
\hline $\begin{array}{l}\text { Mean } \\
\text { SD } \\
\text { n }\end{array}$ & $\begin{array}{r}460 \\
137 \\
4\end{array}$ & $\begin{array}{r}1795 \\
270 \\
4\end{array}$ \\
\hline \multicolumn{3}{|c|}{ Multiparas } \\
\hline $\begin{array}{l}\text { Mean } \\
\text { SD } \\
\text { n }\end{array}$ & $\begin{array}{r}628 \\
53 \\
2\end{array}$ & $\begin{array}{r}1305 \\
297 \\
2\end{array}$ \\
\hline
\end{tabular}

Result of two-way analysis of variance

on interaction of parity and treatment :

$\mathrm{F}(138)=6.83 ; \mathrm{p}=0.03$.

women the amount of milk was greater in the multiparas than the primiparas, whereas in the women given oxytocin the reverse was the case. Table III shows the concentrations of components of milk in the women who had given birth at term and those who had given birth prematurely and received oxytocin or placebo. Using the Scheffé method of multiple comparison ${ }^{18}$ separately for the data on the third and fifth days after birth, we could not show significant differences in any of the components analysed between these groups. No side effects were noted.

\section{Discussion}

In this double-blind sequential clinical trial we studied the effect of an oxytocin nasal spray on women using a breast pump to induce lactation after having given birth prematurely. During the investigation the beneficial effect of the spray in some women was so obvious that the double-blind character of the study was partially lost. The effect of the spray proved to be highly significant, resulting in a 3.5 -fold increase in milk in primiparas and a twofold increase in multiparas during the first five days after birth. Since this strongly indicates that the effect of oxytocin is greater in primiparas than multiparas breast-feeding for the first time, future studies of methods of enhancing lactation should be performed separately for primiparas and multiparas.

Although the oxytocin nasal spray enhanced lactation, it did not significantly change the composition of the breast milk. Like Atkinson et $a l^{7}$ we found a slightly higher concentration of nitrogen in the milk of mothers who had given birth prematurely compared with mothers who had given birth at term. This difference, however, was not significant, possibly because of the small sample sizes.

Since evidence is accumulating that breast milk from an infant's own mother protects it against many hazards of prematurity ${ }^{2-6}$ stimulating and helping women to lactate is
TABLE III-Mean SD concentrations of components of breast milk on days 3 and 5 after delivery in women who gave birth at term and in placebo-treated and oxytocin-treated women who gave birth prematurely

\begin{tabular}{|c|c|c|c|c|c|}
\hline & & $\begin{array}{l}\text { Delivery } \\
\text { at term } \\
(\mathrm{n}=4)\end{array}$ & $\begin{array}{l}\text { Premature } \\
\text { delivery, } \\
\text { placebo } \\
\text { treated }\end{array}$ & $\begin{array}{c}\text { Premature } \\
\text { delivery, } \\
\text { oxytocin } \\
\text { treated }\end{array}$ & $\begin{array}{l}\text { Multiple } \\
\text { comparison } \\
(\mathrm{p})^{*}\end{array}$ \\
\hline Fat & Day 3 & $25 \cdot 5: 18 \cdot 3$ & $34 \cdot 8+12 \cdot 0$ & $27 \cdot 3 \div 10 \cdot 8$ & 0.61 \\
\hline$(\mathrm{g} / \mathrm{l})$ & Day 5 & $23.8 \quad 16.9$ & $40.0+13.3$ & $32.8: 12.0$ & 0.15 \\
\hline Protein & Day 3 & $24.8+9 \cdot 0$ & $28 \cdot 3: 5 \cdot 3$ & $25.8+11.7$ & 0.88 \\
\hline$(\mathrm{g} / 1)$ & Day 5 & $20 \cdot 2: 3.7$ & $24 \cdot 5: 6.7$ & $18.8: 1.6$ & 0.13 \\
\hline Lactose & Day 3 & $182 \cdot 6: 3.8$ & $165.6 \div 15.8$ & $171 \cdot 8: 12 \cdot 3$ & 0.09 \\
\hline$(\mathrm{mmol} / \mathrm{l})$ & Day 5 & $187 \cdot 6 \div 6 \cdot 1$ & $172.4 \div 18.1$ & $186.4+6.7$ & $0 \cdot 12$ \\
\hline Energy & Day 3 & $2.4: 0.6$ & $2 \cdot 7 \div 0.4$ & $2.4 \div 0.3$ & 0.45 \\
\hline$(\mathrm{MJ} 1)$ & Day 5 & $2 \cdot 3: 0 \cdot 6$ & $2.9 \div 0.5$ & $2.6: 0.5$ & 0.24 \\
\hline Ash & Day 3 & $2 \cdot 30+0 \cdot 22$ & $2 \cdot 83+0 \cdot 37$ & $2.63 \div 0.46$ & 0.08 \\
\hline$(\mathrm{g} / \mathrm{l})$ & Day 5 & $2 \cdot 23: 0.17$ & $2.65: 0.34$ & $2.42 \div 0.33$ & 0.11 \\
\hline Sodium & Day 3 & $16 \cdot 7: 2 \cdot 4$ & $24 \cdot 6+12 \cdot 0$ & 19.099 & $0 \cdot 30$ \\
\hline$(\mathrm{mmol} / \mathrm{l})$ & Day 5 & $14.6+3.9$ & $18 \cdot 6 \pm 8 \cdot 1$ & $13 \cdot 6+2.9$ & 0.24 \\
\hline Potassium & Day 3 & $20 \cdot 4+2 \cdot 6$ & $18.9+4.0$ & $19 \cdot 1+3 \cdot 2$ & 0.73 \\
\hline$(\mathrm{mmol} / \mathrm{l})$ & Day 5 & $20.5+1.9$ & $20 \cdot 8 \pm 1.8$ & $19.2 \div 0.5$ & $0 \cdot 17$ \\
\hline
\end{tabular}

*Each $\mathrm{p}$ value is the result of the overall one-way analysis of variance test in the Scheffé multiple comparison procedurc. ${ }^{1 *}$

Conversion: SI to traditional units-Lactose: $1 \mathrm{mmol} / 1 \approx 0.34 \mathrm{~g} / 1$. Energy: $1 \mathrm{MJ} / 1$ $\approx 239 \mathrm{kcal} / 1$. Sodium: $1 \mathrm{mmol} / 1 \approx 23 \mathrm{mg} / 1$. Potassium: $1 \mathrm{mmol} / 1 \approx 39 \mathrm{mg} / 1$

extremely important. When mothers and infants have to be separated lactation must be induced by manual expression or a breast pump. Many primiparas and multiparas breast-feeding for the first time have great difficulty in inducing lactation in this way. ${ }^{8} 9$ We conclude that inducing lactation with an oxytocin nasal spray is effective, has no ill effects on the mother, and causes no significant changes in the composition of the breast milk.

We thank the nurses of the maternity ward of the Groot Ziekengasthuis for their extensive co-operation. The oxytocin nasal spray was a gift from Sandoz BV, the Netherlands.

\section{References}

${ }^{1}$ Fomon S, Ziegler E, Vazquez H. Human milk and the small premature infant. Am 7 Dis Child 1977;131:463-7.

2 Winberg J, Wessner G. Does breast milk protect against septicaemia of the newborn? Lancet 1971 ; : 1091-4.

${ }^{3}$ Ho P, Lawton J. Human colostral cells: phagocytosis and killing of E coli and $\mathrm{C}$ albicans. $\mathcal{F}$ Pediatr 1978;93:910-5.

4 Barlow B, Santulli W, Heird W, Pitt J. An experimental study of acute neonatal enterocolitis; the importance of breastmilk. I Pediatr Surg $1974 ; 9: 587-95$.

${ }^{5}$ Pitt J, Barlow B, Heird W. Protection against experimental necrotizing enterocolitis by maternal milk. Pediatr Res 1977;11:906-9.

${ }^{6}$ Fomon S. Human milk in premature infant feeding: report of a second workshop. Am f Public Health 1977;67:361-3.

${ }^{7}$ Atkinson S, Bryan M, Anderson G. Human milk: difference in nitrogen concentration in milk from mothers of term and premature infants. 7 Pediatr 1978;93:67-9.

${ }^{8}$ Choi M. Breastmilk for infants who can't breastfeed. Am $\mathcal{F}$ Nurs $1978 ; 78$ : 852-5.

${ }^{9}$ Stewart D, Gaiser C. Supporting lactation when mothers and infants are separated. Nurs Clin North Am 1978;13:47-61.

10 Aono T, Shioji T, Aki T, et al. Augmentation of puerperal lactation by oral administration of sulpiride. F Clin Endocrinol Metab 1979;48:478-82.

11 Brown R. Relactation with reference to application in developing countries. Clin Pediatr 1978;17:333-7.

12 Lincoln $D$. Does a mechanism of negative feedback determine the intermittent release of oxytocin during suckling ? F Endocrinol $1974 ; 60: 193-4$.

13 Ingerslev $\mathrm{M}$, Pinholt $\mathrm{K}$. Oxytocin treatment during the establishment of lactation. Acta Obstet Gynecol Scand 1962;41:159-68.

${ }^{14}$ Luhman L. The effect of intranasal oxytocin on lactation. Am $\mathcal{F}$ Obstet Gynecol 1963;21:713-7.

15 Pocock S. Group sequential methods in the design and analysis of clinical trials. Biometrika 1977;64:191-9.

16 Koops J, Klomp H, Elgersma RHC. Rapid determination of nitrogen in milk and dairy products by colorimetric estimation of ammonia following an accelerated digestion procedure. Netherlands Milk Dairy fournal 1975;29:169-80.

16a Weide AJ, Dagneaux ELK. De bereiding van het koper proefvocht volgens Luff-Schoorl. Chemisch Weekblad 1961;57:46-7.

17 Southgate D, Durnin J. Calorie conversion factors. Br f Nutr 1970;24: 517-35.

18 Scheffé H. The analysis of variance. New York: John Wiley and Sons, 1959.

(Accepted 2 Fune 1981) 